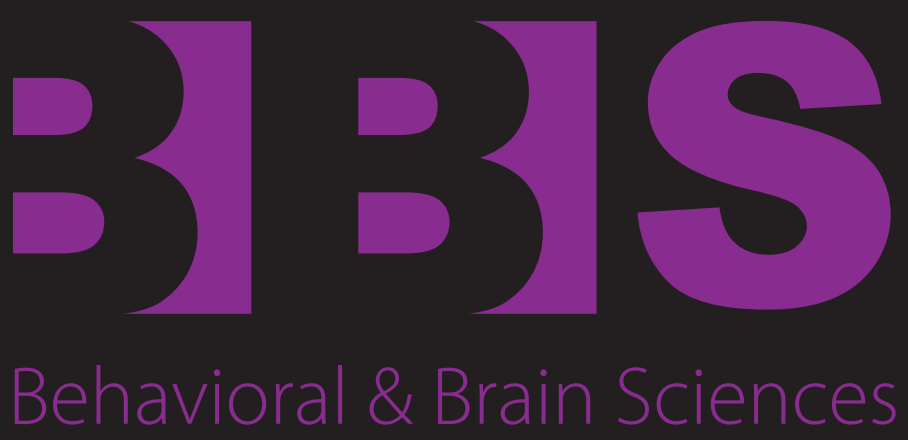

An International journal of current research and theory with open peer commentary

Volume 35 | Issue 4 | August 2012 | ISSN: 0140-525X 
Editors

Paul Bloom

Barbara L. Finlay

URL: http://www.editorialmanager.com/bbs

E-mail: bbsjournal@cambridge.org

Behavioral and Brain Sciences

Journals Department

Cambridge University Press

32 Avenue of The Americas

New York, NY 10013-2473, U.S.A.

\section{Managing Editor}

Gennifer Levey

\section{Chief Copy Editor}

Sumitra Mukerji

Proofreaders

Sylvia Elvin

Rashidah Ismaili AbuBakr

\section{Editorial Board}

Affective Neuroscience

Stephanie D. Preston/U. of Michigan

Atypical Neurodevelopment

Simon Baron-Cohen/Cambridge U.

Behavioral Neurogenetics

Wim E. Crusio/CNRS UMR

Cognition and Artificial Intelligence

Zenon Pylyshyn/Rutgers U.

Cognitive and Decision Sciences

Nick Chater/University College London

Cognitive Development

Annette Karmiloff-Smith/Birbeck College

Cognitive Neuroscience

Moshe Bar/Harvard Medical School

Computational Neuroscience

Nestor A. Schmajuk/Duke U.

Evolution of Brain and Cognition

Dean Falk/Florida State U.

Evolution of Cognition

Celia Heyes/Oxford U.

Experimental Analysis of Behavior

A. Charles Catania/U. Maryland, Baltimore County

Language and Language Disorders

Max Coltheart/Macquarie U.

Linguistics

Robert A. Freidin/Princeton U.

Perception

Bruce Bridgeman/U. of California, Santa Cruz

Philosophy of Science

Massimo Piattelli-Palmarini/U. of Arizona

Primate Cognition

Laurie R. Santos/Yale U.

Social Cognition

Mahzarin R. Banaji/Harvard U.

Social Cognitive Neuroscience

Rebecca Saxe/MIT

Vision, Language and Computation

Shimon Edelman/Cornell U.
Editorial Policy Behavioral and Brain Sciences (BBS) is an international journal providing a special service called Open Peer Commentary* to researchers in any area of psychology, neuroscience, behavioral biology, or cognitive science who wish to solicit, from fellow specialists within and across these BBS disciplines, multiple responses to a particularly significant and controversial piece of work. (See Instructions for Authors and Commentators, inside back cover and also at http://journals.cambridge.org/BBSJournal/Inst) The purpose of this service is to contribute to the communication, criticism, stimulation, and particularly the unification of research in the behavioral and brain sciences, from molecular neurobiology to artificial intelligence and the philosophy of mind.

Papers judged by the editors and referees to be appropriate for Commentary are circulated to a large number of commentators selected by the editors, referees, and author to provide substantive criticism, interpretation, elaboration, and pertinent complementary and supplementary material from a full cross-disciplinary perspective. The article, accepted commentaries, and the author's response then appear simultaneously in BBS.

Commentary on BBS articles may be provided by any qualified professional in the behavioral and brain sciences, but much of it is drawn from a large body of BBS Associates who have become formally affiliated with the project (see http://journals.cambridge.org/BBSJournal/ BBSAssoc).

Qualified professionals are eligible to become BBS Associates if they have (1) been nominated by a current BBS Associate, (2) refereed for BBS, or (3) had a commentary or article accepted for publication. A special subscription rate is available to Associates. Individuals interested in serving as BBS Associates are asked to view the full instructions for joining at http://journals.cambridge.org/BBSJournal/Inst/Assoc and then email bbsjournal@ cambridge.org.

(C) Cambridge University Press 2012. All rights reserved. No part of this publication may be reproduced, in any form or by any means, electronic, photocopying, or otherwise, without permission in writing from Cambridge University Press. Policies, request forms, and contacts are available at: http://www.cambridge.org/rights/permissions/permission.htm.

Permission to copy (for users in the U.S.A.) is available from Copyright Clearance Center, http://www.copyright.com, email:info @ copyright.com.

Subscriptions Behavioral and Brain Sciences (ISSN 0140-525X) is published bimonthly in February, April, June, August, October, and December. The subscription price of Volume 35 (2012) for institutions is US $\$ 1193.00$ for print and online, US $\$ 1005.00$ for online only, and US $\$ 1093.00$ for print only in the U.S.A., Canada, and Mexico; and UK $£ 703.00$ for print and online, UK $£ 594.00$ for online only, and UK $£ 643.00$ for print only elsewhere. The subscription price for individuals is US $\$ 346.00$ for print and online and US $\$ 321.00$ for print only in the U.S.A., Canada, and Mexico; and UK £203.00 for print and online and UK $£ 189.20$ for print only elsewhere. For BBS Associates, with proof of eligibility with order, US $\$ 132.00$ in the U.S.A., Canada, and Mexico; and UK $£ 83.00$ elsewhere. For students, with proof of eligibility with order, $\$ 111.00$ in the U.S.A., Canada, and Mexico; and UK $£ 65.00$ elsewhere. Subscription price includes surface postage. Single parts cost US $\$ 238.00$ (UK $£ 118.00)$ plus postage. Institutional orders may be sent to a bookseller, or, in the U.S.A., Canada, and Mexico direct to: Cambridge University Press, 32 Avenue of The Americas, New York, NY 10013-2473 email: journals subscriptions@cambridge.org; in the U.K. and rest of the world to: Cambridge University Press, The Edinburgh Building, Shaftesbury Road, Cambridge CB2 8RU, England, e-mail:journals_subscriptions@cambridge.cam.ac.uk. Individuals must order direct from the Press. You may also subscribe through the Cambridge Journals website, http://journals.cambridge.org/bbs.

Postmaster: Send address changes in the U.S.A., Canada, and Mexico to Behavioral and Brain Sciences, Cambridge University Press, Journals Dept., 100 Brook Hill Drive, West Nyack, NY 10994-2133, U.S.A. Send address change elsewhere to Behavioral and Brain Sciences, Cambridge University Press, The Edinburgh Building, Shaftesbury Road, Cambridge CB2 8RU, England.

Online availability Behavioral and Brain Sciences is part of the Cambridge Journals Online (CJO) service at http://journals.cambridge.org.

Institutional subscribers: Access to full-text articles online is currently included with the cost of the print subscription. Subscription must be activated; see http://cambridge.journals.org.

Advertising Inquiries about advertising should be sent to the Journals Advertising Department of the Cambridge or New York Office of Cambridge University Press.

\section{FOUNDING EDITOR (1978-2001)}

Stevan Harnad 


\section{Contents Volume 35:4 August 2012}

Vaesen, K. The cognitive bases of human tool use

\section{Open Peer Commentary}

Arbib, M. A. Tool use and constructions

Barceló-Coblijn, L. \& Gomila, A. Evidence

of recursion in tool use

Beck, S. R., Chappell, J., Apperly, I. A. \&

Cutting, N. Tool innovation may be a critical

limiting step for the establishment of a rich

tool-using culture: A perspective from

child development

Blitzer, A. \& Huebner, B. Tool use as situated cognition

Cachel, S. Human tool behavior is species-specific and remains unique

Crabb, P. B. Technological selection:

A missing link

Dounskaia, N. Unique features of human movement control predicted by the leading joint hypothesis

Gainotti, G. Brain structures playing a crucial role in the representation of tools in humans and non-human primates

Gibson, K. R. Human tool-making capacities reflect increased information-processing capacities: Continuity resides in the eyes of the beholder

Holloway, R. L. Language and tool making are similar cognitive processes

IJzerman, H. \& Foroni, F. Not by thoughts alone: How language supersizes the cognitive toolkit

Jacquet, P. O., Tessari, A., Binkofski, F. \& Borghi, A. M. Can object affordances impact on human social learning of tool use?

Jeffares, B. Thinking tools: Acquired skills, cultural niche construction, and thinking with things

Longo, M. R. \& Serino, A. Tool use induces complex and flexible plasticity of human body representations

Malafouris, L. Prosthetic gestures: How the tool shapes the mind

Moerman, D. E. Cathedrals, symphony orchestras,

218

219

technology

Nielsen, M. Childhood and advances in

human tool use

Nonaka, T. What exists in the environment that motivates the emergence, transmission, and sophistication of tool use?

220 Orban, G. A. \& Rizzolatti, G. An area specifically devoted to tool use in human left inferior

221 parietal lobule

Osvath, M., Persson, T. \& Gärdenfors, P.

222 Foresight, function representation, and social intelligence in the great apes

222 Patterson, E. M. \& Mann, J. Look, no hands! Penn, D. C., Holyoak, K. J. \& Povinelli, D. J. So, are we the massively lucky species?

223 Ragir, S. \& Brooks, P. J. The key to cultural innovation lies in the group dynamic rather than in the individual mind

224 Reader, S. M. \& Hrotic, S. M. The limits of chimpanzee-human comparisons for understanding human cognition

Rizzo, A. The dual nature of tools and their makeover

Taylor, A. H. \& Clayton, N. S. Evidence from convergent evolution and causal reasoning suggests that conclusions on human uniqueness may be premature

Tennie, C. \& Over, H. Cultural intelligence is key to explaining human tool use

Vingerhoets, G. Neurocognitive anthropology: What are the options?

Rosenbaum, D. A. Motor planning in primates 